http://dx.doi.org/10.32929/2446-8355.2020v29n1p92-105

\title{
EFEITO DO ARMAZENAMENTO EM CULTIVARES DE FEIJOEIRO PARA COMERCIALIZAÇÃO
}

\section{Carolina Cipriano Pinto ${ }^{1 *}$, Camila Baptista Amaral ${ }^{1}$, Carina Oliveira e Oliveira ${ }^{1}$, Jordana de Araújo Flôres ${ }^{1}$, Leandro Borges Lemos ${ }^{2}$}

\begin{abstract}
${ }^{1}$ Engenheira Agrônoma Doutora, área de fitotecnia, Faculdade de Ciências Agrárias e Veterinárias, Universidade Estadual Paulista (UNESP), Jaboticabal, SP. *E-mail do autor correspondente: carolina.ccp@ hotmail.com ${ }^{2}$ Professor Doutor do Departamento de Produção Vegetal, Faculdade de Ciências Agrárias e Veterinárias, Universidade Estadual Paulista (UNESP), Jaboticabal, SP.
\end{abstract}

Recebido: 02/11/2018; Aceito: 27/03/2020

RESUMO: Os consumidores de feijão são exigentes quanto às características grão, demandando baixo tempo de cozimento, alta capacidade de hidratação e qualidade proteica. Entretanto esses atributos durante o armazenamento podem ser alterados, levando à perda de qualidade. $\mathrm{O}$ objetivo deste trabalho foi avaliar os atributos qualitativos de cultivares de feijoeiro do grupo comercial carioca durante o armazenamento. O delineamento utilizado foi inteiramente casualizado, em esquema fatorial $13 \times 3$, constituído por cultivares de feijoeiro (Pérola, BRSMG Majestoso, BRS Estilo, BRSMG Madrepérola, IPR Campos Gerais, IPR Tangará, IPR Andorinha, IPR 139, IAC Imperador, IAC Formoso, IAC Alvorada, IAC Milênio e Bola Cheia) e três tempos de armazenamento (grãos recém colhidos, com quatro e oito meses após a colheita), com quatro repetições. Foram avaliados a coloração do tegumento, teor de proteína bruta, tempo de cozimento, relação de hidratação e tempo para máxima hidratação. O período de armazenamento não altera significativamente os atributos qualitativos dos grãos, mantendo a maioria das características essenciais ao mercado consumidor. A BRSMG Madre pérola não apresentou alteração na cor do tegumento, e o menor tempo de cozimento foi apresentado pela cultivar IPR Andorinha. O escurecimento dos grãos de feijão não está associado com o aumento do tempo de cozimento. Todas as cultivares apresentam resultado satisfatório para o tempo de máxima hidratação e a relação de hidratação.

Palavras chave: Phaseolus vulgaris. Genótipos. Tempo de cozimento. Hidratação dos grãos. Cor do tegumento.

\section{EFFECT OF STORAGE ON BEAN CULTIVARS FOR COMMERCIALIZATION}

ABSTRACT: Beanconsumers are demanding about the grain characteristics, requiring low cooking time, high hydration capacity and, protein quality. However these attributes during storage can be altered, resulting in loss of quality The objective of this study was to evaluate the qualitative attributes of common bean cultivars of "carioca" commercial group during storage. The design was completely randomized in a factorial scheme $13 \times 3$, consisting of bean cultivars (Pérola, BRSMG Majestoso, BRS Estilo, BRSMG Madrepérola, IPR Campos Gerais, IPR Tangará, IPR Andorinha, IPR 139, IAC Imperador, IAC Formoso, IAC Alvorada, 
IAC Milênio and Bola Cheia) and three storage times (freshly harvested grains, four and eight months after harvest), with four replications. Thetegmunt color, crude protein content, cooking time, hydration ratio and time to maximum hydration were evaluated. The storage period does not significantly alter the qualitative attributes of grains, mateining the most essential characteristics to the consumer market. The BRSMG Madrepérola did not presented alteration of the grain tegument color, and IPR Andorinha stood out with shorter cooking time. This study shows that the darkening of the beans is not associated with increase of the cooking time. All cultivars have satisfactory result for maximum hydration time and hydration ratio.

Key words: Phaseolus vulgaris. Genotypes. Cooking time. Grain hydration. Tegument color.

\section{INTRODUÇÃO}

No comércio de grãos de feijão, atributos qualitativos como menor tempo para o cozimento, alta capacidade de hidratação e qualidade proteica são preferidos pelos consumidores (BURATTO et al., 2009; COELHO et al., 2008; FARINELLI; LEMOS, 2010; MINGOTTE et al., 2013; OLIVEIRA et al., 2013; PERINA et al., 2010; RAMOS JUNIOR et $a l ., 2005 \mathrm{a})$. No entanto, durante o seu armazenamento alguns destes atributos são alterados, e os prejuízos são expressos principalmente pelo aumento do tempo de cozimento e escurecimento do tegumento, o que leva perda de valor comercial (LIMA et al., 2014).

O aumento no tempo de cozimento se deve à presença de grãos maduros e secos que não absorvem água durante a embebição, ou apenas absorvem água quando submetido a um longo período em água fervente (OLIVEIRA et al., 2011). Tais tipos de grãos são denominados hardshell e hard-tocook, sendo que hardshell refere-se à impermeabilidade do tegumento à água, e o hard-tocook representam os grãos que absorvem água, e não amolecem durante o cozimento (BOURNE, 1967; VINDIOLA et al., 1986).

Outro problema decorrente do armazenamento é o escurecimento dos grãos, que é associado pelos consumidores aos grãos duros e de má qualidade sensorial, tendo baixa aceitação no comércio (NASIR-ABBAS et al., 2008). Essa característica dos grãos é avaliada pela claridade da cor do tegumento (luminosidade ("L")), genótipos capazes de manter essa característica inalterada durante o armazenamento terão maior aceitação do mercado consumidor (RIBEIRO et al., 2008).

Durante o armazenamento, podem haver alterações na claridade dos grãos (valor de 'luminosidade $\left.\left(\mathrm{L}^{*}\right)^{\prime}\right)$, e genótipos capazes de manter essa característica inalterada durante o armazenamento terão maior aceitação (RIBEIRO et al., 2008). Além da coloração, os programas de melhoramento de feijão têm buscado o aumento de produtividade, tolerância à pragas e doenças, maior tamanho dos grãos e tempo de cozimento aceitável no mercado (PERINA et al., 2014).

Segundo o site do Ministério da Agricultura, Pecuária e Abastecimento - MAPA (BRASIL, 2016) há 326 registros de cultivares feijão, e a cada ano são lançados novos cultivares. Em função da importância dos atributos qualitativos dos grãos de feijão 
comercializados e da frequente necessidade de armazenamento do produto, o presente trabalho teve por objetivo avaliar os atributos qualitativos de cultivares de feijoeiro do grupo comercial carioca em função de períodos de armazenamento.

\section{MATERIAL E MÉTODOS}

O trabalho foi conduzido na Universidade Estadual Paulista campus de Jaboticabal (SP), situada na latitude de $21^{\circ} 15^{\prime} 22^{\prime \prime} \mathrm{S}$ e longitude $48^{\circ} 18^{\prime} 58^{\prime}$ W, a $565 \mathrm{~m}$ de altitude. O clima da região é tipo Aw, tropical úmido com estação chuvosa no verão e seca no inverno.

$\mathrm{O}$ delineamento experimental foi inteiramente casualizado, com quatro repetições. $\mathrm{O}$ experimento constituiu-se de um fatorial 13 × 3, sendo 13 cultivares de feijoeiro do grupo comercial carioca (Pérola, BRSMG Majestoso, BRS Estilo, BRSMG Madrepérola, IPR Campos Gerais, IPR Tangará, IPR Andorinha, IPR 139 [Juriti Claro], IAC Imperador, IAC Formoso, IAC Alvorada, IAC Milênio e Bola Cheia) e três períodos de armazenamento (recém colhido, quatro meses e oito meses após a colheita).

A colheita foi realizada após os grãos atingirem a maturidade fisiológica, sendo realizado o arranquio manual das plantas, que foram colocadas para secagem a pleno sol e, posteriormente, trilhadas mecanicamente (15/11/2013), padronizando o teor de umidade dos grãos para $13 \%$ b.u. Após a pesagem dos grãos, procedeu-se o rendimento de peneira. As amostras retidas na peneira 13 (13/64" pol.) foram utilizadas nas avaliações dos atributos qualitativos.

Para avaliação dos grãos durante o armazenamento, estes foram acondicionados em sacos plásticos hermeticamente fechados $(15,5 \times 12 \mathrm{~cm})$, contendo $340 \mathrm{~g}$ de feijão em cada, utilizando quatro sacos por cultivar. As amostras permaneceram no laboratório sob condições ambientais durante oito meses (janeiro a agosto de 2014). O controle das condições ambientais foi feito utilizando o termo higrômetro da marca Cetec e modelo 7663.02.0.00, procedendo-se leituras semanais de temperaturas $\left({ }^{\circ} \mathrm{C}\right)$ máximas e mínimas e umidade relativa do ar (\%) do ambiente, obtendo-se média da temperatura de $24,7^{\circ} \mathrm{C}$ e umidade relativa do ar de $51 \%$ considerando todo o período. $\mathrm{O}$ aparelho possui sensor que foi acondicionado no interior de uma amostra para aferir a temperatura máxima e mínima e a umidade, mostrando que a média de temperatura foi de $23,7^{\circ} \mathrm{C}$ e umidade relativa do ar de $51 \%$ (Figura 1).

$\mathrm{O}$ teor de proteína bruta $(\mathrm{PB} \%)$ foi determinado pela quantidade de nitrogênio $(\mathrm{N})$ contido nos grãos e realizado o cálculo: $\mathrm{PB}=(\mathrm{N}$ total $\times 6,25)$ no qual, $\mathrm{PB}=$ teor de proteína bruta nos grãos $\left(\mathrm{g} \mathrm{kg}^{-1}\right)$ e $\mathrm{N}$ total $=$ teor de $\mathrm{N}$ nos grãos.

A cor do tegumento dos grãos foi determinada com o auxílio de um colorímetro, por meio da leitura de luminosidade ("L"), que avalia a claridade da cor da amostra com variação de 0 a 100, ou seja, quanto maior o valor de "L", mais clara é a coloração do tegumento (RIBEIRO; STORCK, 2003; RIBEIRO et al., 2008).

O tempo para cozimento (minutos) foi determinado com o auxílio do cozedor de Mattson, com temperatura da água mantida a $96^{\circ} \mathrm{C}$. Para essa determinação os grãos foram hidratados previamente em água destilada durante um período de 16 horas. De posse dos 
dados, adotou-se a escala de Proctor e Watts (1987) para verificar o nível de resistência ao cozimento, sendo representado por: muito suscetível ao cozimento com tempo inferior a 16 minutos, de 16 a 20 minutos como suscetibilidade média ao cozimento, de 21 a 29 minutos como resistência normal ao cozimento, de 29 a 32 minutos como resistência média ao cozimento, de 33 a 36 minutos como resistente ao cozimento e tempo superior 36 minutos como muito resistente ao cozimento.

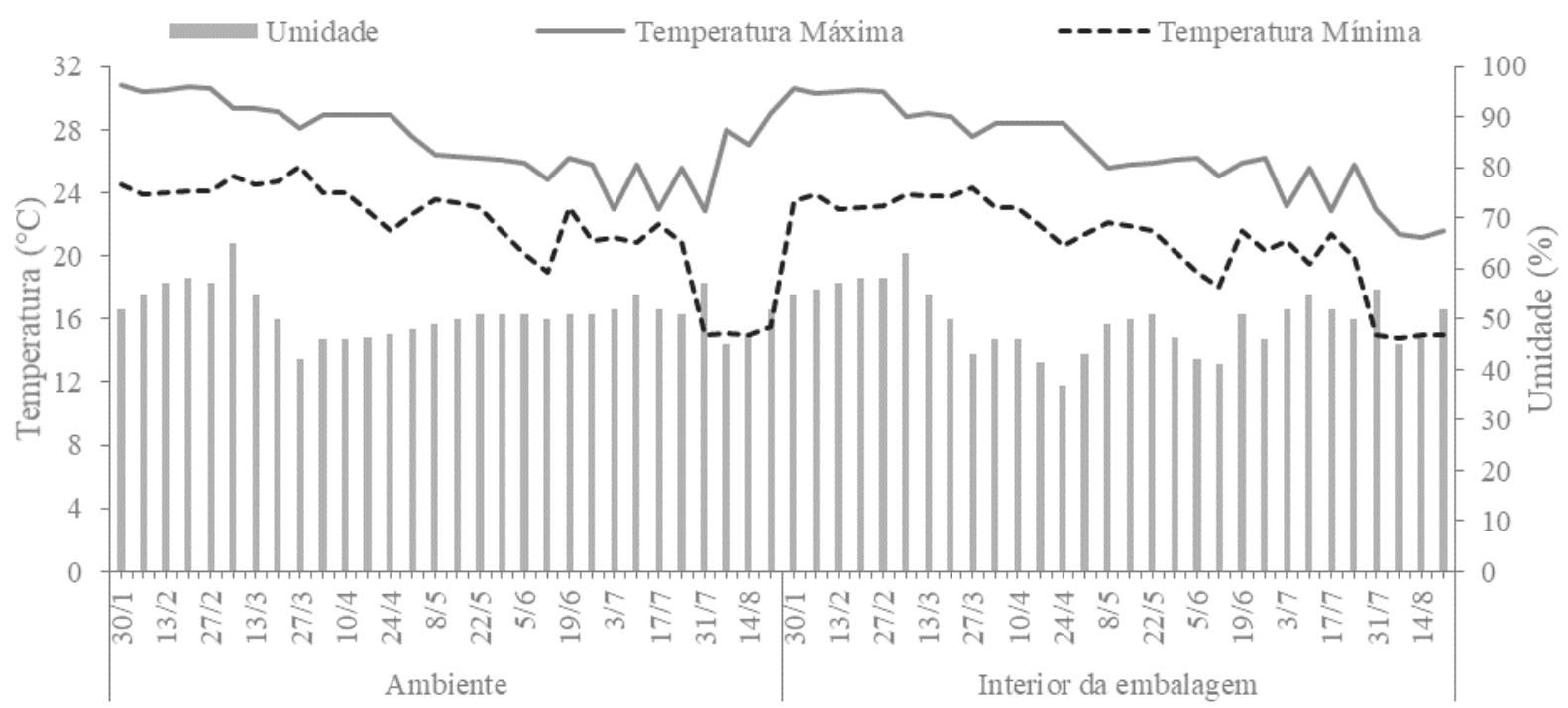

Figura 1. Temperaturas máximas e mínimas e umidade relativa registradas do ambiente e no interior da embalagem durante o armazenamento das cultivares de feijão do grupo comercial carioca, 2014. Jaboticabal, SP. Maximum and minimum temperatures and relative humidity recorded from the environment and inside the package during the storage of bean cultivars of the carioca commercial group, 2014. Jaboticabal, SP.

Fonte: Autoria própria. Own authorship.

A capacidade de hidratação foi determinada durante 20 horas, onde a cada 2 horas foram feitas avaliações do volume de água não absorvido pelos grãos, vertendo-a do béquer para proveta. Ao final do tempo previsto para a hidratação, a água foi totalmente drenada e os grãos pesados, com isso foi efetuada a relação de hidratação, determinada pela a razão entre a massa após a hidratação e a massa inicial dos grãos. Foi realizado o estudo de regressão polinomial entre o tempo (horas) e a capacidade de hidratação $(\mathrm{mL})$, para determinar o tempo necessário para ocorrer a máxima hidratação dos grãos.

Os dados foram submetidos à análise de variância pelo teste $\mathrm{F}(\mathrm{p}<0,05)$ e as médias agrupadas pelo teste Scott-Knott $(\mathrm{p}<0,05)$. Realizou-se o estudo de correlação linear simples entre os atributos mensurados. A significância da regressão polinomial e das correlações foi avaliada pelo teste $\mathrm{t}(\mathrm{p}<0,05)$.

\section{RESULTADOS E DISCUSSÃO}

Houve interação entre as cultivares e o armazenamento para os parâmetros cor de tegumento dos grãos, teor de proteína e tempo de cozimento, não havendo interação para relação de hidratação e tempo para máxima hidratação (Tabela 1). 
Para relação de hidratação, as cultivares BRS Pérola, BRSMG Madrepérola, IAC Alvorada, IAC Formoso e IPR Tangará apresentaram maiores valores, diferindo significativamente das demais (Tabela 1). Por outro lado, todas as cultivares apresentaram valores próximos a 2,0, resultado considerado satisfatório (RAMOS JUNIOR et al., 2005b; FARINELLI; LEMOS, 2010; MINGOTTE et al., 2013). Ramos Junior, Lemos e Silva (2005a) obtiveram valores semelhantes durante o armazenamento por seis meses, evidenciando que o armazenamento não foi prejudicial para esta característica dos grãos.

Tabela 1. Valores de F e médias de cor do tegumento, teor de proteína bruta (TB), tempo de cozimento (COZ), relação de hidratação $(\mathrm{RH})$ e tempo para máxima hidratação (MAXH) dos grãos de cultivares de feijão do grupo comercial carioca durante o armazenamento, 2014. Jaboticabal, SP ${ }^{(1)}$. F values and color means of the tegument, crude protein (TB), cooking time (COZ), hydration ratio (RH) and time for maximum hydration (MAXH) of bean cultivars of the "carioca" commercial group, 2014. Jaboticabal, $S P^{(1)}$.

\begin{tabular}{|c|c|c|c|c|c|c|c|c|}
\hline \multirow{2}{*}{ Cultivares } & \multicolumn{4}{|c|}{ Cor do tegumento } & \multirow{2}{*}{$\frac{\mathrm{TB}}{--(\%)--}$} & \multirow{2}{*}{$\frac{\mathrm{COZ}}{-(\min )-}$} & \multirow{2}{*}{$\begin{array}{c}\text { RH } \\
------\end{array}$} & \multirow{2}{*}{$\frac{\text { MAXH }}{-(\mathrm{h}: \min )-}$} \\
\hline & $\mathrm{L}$ & $\mathrm{a}$ & $\mathrm{b}$ & $\mathrm{C}$ & & & & \\
\hline BRS Pérola & 46,49 & 11,47 & 16,71 & 20,28 & 18,1 & 25 & $2,03 \mathrm{a}$ & $15: 17 \mathrm{a}$ \\
\hline BRS Estilo & 47,37 & 11,07 & 16,30 & 19,71 & 19,0 & 28 & $1,99 \mathrm{~b}$ & $14: 42 \mathrm{c}$ \\
\hline BRSMG Madrepérola & 54,62 & 7,27 & 16,35 & 17,90 & 19,1 & 31 & $2,02 \mathrm{a}$ & $15: 27 \mathrm{a}$ \\
\hline BRSMG Majestoso & 46,06 & 10,97 & 16,50 & 19,82 & 19,1 & 29 & $1,99 \mathrm{~b}$ & $15: 21 \mathrm{a}$ \\
\hline IAC Alvorada & 48,77 & 10,28 & 16,36 & 19,33 & 19,7 & 24 & $2,04 \mathrm{a}$ & $15: 13 \mathrm{a}$ \\
\hline IAC Formoso & 48,69 & 10,16 & 16,39 & 19,29 & 19,4 & 25 & $2,04 \mathrm{a}$ & $15: 04 b$ \\
\hline IAC Imperador & 47,22 & 11,81 & 17,44 & 21,07 & 19,0 & 25 & $2,00 \mathrm{~b}$ & $15: 12 \mathrm{a}$ \\
\hline IAC Milênio & 48,05 & 11,19 & 17,24 & 20,57 & 20,0 & 29 & $1,98 \mathrm{~b}$ & $14: 59 \mathrm{~b}$ \\
\hline IPR Andorinha & 46,14 & 11,69 & 18,10 & 21,56 & 17,7 & 25 & $2,00 \mathrm{~b}$ & $15: 27 \mathrm{a}$ \\
\hline IPR Campos Gerais & 47,50 & 9,94 & 15,81 & 18,69 & 17,8 & 29 & $2,01 \mathrm{~b}$ & $15: 19 \mathrm{a}$ \\
\hline IPR 139 & 46,84 & 11,15 & 17,39 & 20,68 & 19,4 & 28 & $2,00 \mathrm{~b}$ & $15: 42 \mathrm{a}$ \\
\hline IPR Tangará & 47,79 & 10,71 & 16,59 & 19,75 & 19,1 & 27 & $2,05 \mathrm{a}$ & $15: 20 \mathrm{a}$ \\
\hline Bola Cheia & 47,49 & 10,68 & 16,32 & 19,52 & 18,7 & 28 & $2,02 \mathrm{~b}$ & $15: 25 \mathrm{a}$ \\
\hline \multicolumn{9}{|l|}{ Armazenamento (meses) } \\
\hline 0 & 50,92 & 9,21 & 15,82 & 18,32 & 20,3 & 23 & $1,98 \mathrm{c}$ & $15: 08$ a \\
\hline 4 & 46,64 & 10,63 & 16,22 & 19,42 & 19,0 & 27 & $2,03 \mathrm{a}$ & $15: 14 \mathrm{a}$ \\
\hline 8 & 46,22 & 12,10 & 18,15 & 21,84 & 17,5 & 31 & $2,02 \mathrm{~b}$ & $15: 24 b$ \\
\hline Média & 47,92 & 10,65 & 16,73 & 19,86 & 18,9 & 27 & 2,01 & $15: 16$ \\
\hline \multicolumn{9}{|l|}{ Teste F } \\
\hline Cultivares (C) & $139,85 * *$ & $227,02 * *$ & $29,13 * *$ & $59,70 * *$ & $9,22 * *$ & $73,59 * *$ & $4,58 * *$ & $6,49 * *$ \\
\hline Armazenamento (A) & $860,99 * *$ & $1519,27 * *$ & $494,60 * *$ & $859,80 * *$ & $160,95 * *$ & $1285,91 * *$ & $20,49 * *$ & $11,10 * *$ \\
\hline Interação C x A & $8,05 * *$ & $8,40 * *$ & $5,91 * *$ & $6,73 * *$ & $4,17 * *$ & $29,92 * *$ & $1,21^{\mathrm{ns}}$ & $0,90^{\mathrm{ns}}$ \\
\hline $\mathrm{CV}(\%)$ & 1,49 & 2,81 & 2,70 & 2,49 & 4,23 & 3,28 & 1,91 & 2,20 \\
\hline
\end{tabular}

(1) Médias seguidas de letras distintas na coluna diferem estatisticamente pelo teste de Scott e Knott $(\mathrm{P}<0,05) .{ }^{\mathrm{ns}}$ $=$ Diferenças não significativas. **Significativo a $1 \%$ de probabilidade. ${ }^{(1)}$ Means followed bt distinctve letters in column differ statistically by Scott and Knott test $\left((P<0,05) .{ }^{n s .}=\right.$ Non-significant differences. $* *$ Significant at $1 \%$ probability.

Fonte: Autoria própria. Own authorship.

As equações de regressão entre o tempo de hidratação e a quantidade de água absorvida pelos grãos das cultivares de feijão estão apresentadas na Tabela 2. Verificou-se que o tempo para hidratação máxima variou entre 14:42 horas (BRS Estilo) e 15:42 horas (IPR 139). A 
diferença entre o tempo para máxima hidratação das cultivares podem estar associadas à rigidez do tegumento, aderência dos cotilédones, elasticidade, porosidade e propriedades coloidais na absorção de água pelos grãos (ESTEVES et al., 2002).

Tabela 2. Equação de regressão entre o tempo para hidratação de grãos e quantidade de água absorvida pelos grãos de cultivares de feijão do grupo comercial carioca recém colhido (0) e durante o armazenamento (4 e 8 meses), 2014. Jaboticabal, SP. Regression equation between grain hydration time and quantity of water absorbed by bean cultivars of the "carioca" commercial group newly harvested (0) and during storage (4 and 8 months), 2014. Jaboticabal, SP.

\begin{tabular}{|c|c|c|}
\hline Cultivares & Equação de regressão $^{(1)}$ & $\mathrm{R}^{2}$ \\
\hline \multirow{3}{*}{ BRS Pérola } & $\mathrm{y}_{0}=-0,000048 \mathrm{x}^{2}+0,0880 \mathrm{x}+9,9222$ & $0,882 * *$ \\
\hline & $\mathrm{y}_{4}=-0,000055 \mathrm{x}^{2}+0,1001 \mathrm{x}+7,8690$ & $0,933 * *$ \\
\hline & $\mathrm{y}_{8}=-0,000048 \mathrm{x}^{2}+0,0880 \mathrm{x}+9,9222$ & $0,896 * *$ \\
\hline \multirow{3}{*}{ BRS Estilo } & $\mathrm{y}_{0}=-0,000046 \mathrm{x} 2+0,0803 \mathrm{x}+13,6380$ & $0,751 * *$ \\
\hline & $\mathrm{y}_{4}=-0,000055 \mathrm{x}^{2}+0,0964 \mathrm{x}+9,0393$ & $0,899 * *$ \\
\hline & $\mathrm{y}_{8}=-0,000051 \mathrm{x}^{2}+0,0905 \mathrm{x}+11,4202$ & $0,844 * *$ \\
\hline \multirow{3}{*}{ BRSMG Madrepérola } & $\mathrm{y}_{0}=-0,000049 \mathrm{x}^{2}+0,0881 \mathrm{x}+10,3929$ & $0,869 * *$ \\
\hline & $\mathrm{y}_{4}=-0,000052 \mathrm{x}^{2}+0,0969 \mathrm{x}+6,7101$ & $0,944 * *$ \\
\hline & $\mathrm{y}_{8}=-0,000047 \mathrm{x}^{2}+0,0901 \mathrm{x}+8,6930$ & $0,917 * *$ \\
\hline \multirow{3}{*}{ BRSMG Majestoso } & $\mathrm{y}_{0}=-0,000045 \mathrm{x}^{2}+0,0814 \mathrm{x}+9,8313$ & $0,868 * *$ \\
\hline & $y_{4}=-0,000053 x^{2}+0,0980 x+6,8171$ & $0,942 * *$ \\
\hline & $\mathrm{y}_{8}=-0,000047 x^{2}+0,0885 x+8,1060$ & $0,912 * *$ \\
\hline \multirow{3}{*}{ IAC Alvorada } & $\mathrm{y}_{0}=-0,000048 \mathrm{x}^{2}+0,0869 \mathrm{x}+10,8018$ & $0,862 * *$ \\
\hline & $\mathrm{y}_{4}=-0,000058 \mathrm{x}^{2}+0,1037 \mathrm{x}+7,2482$ & $0,943 * *$ \\
\hline & $\mathrm{y}_{8}=-0,000049 x^{2}+0,0909 x+9,2669$ & $0,899 * *$ \\
\hline \multirow{3}{*}{ IAC Formoso } & $\mathrm{y}_{0}=-0,000050 \mathrm{x} 2+0,0886 \mathrm{x}+11,3976$ & $0,848 * *$ \\
\hline & $\mathrm{y}_{4}=-0,000057 \mathrm{x}^{2}+0,1016 \mathrm{x}+9,1061$ & $0,915 * *$ \\
\hline & $\mathrm{y}_{8}=-0,000051 \mathrm{x}^{2}+0,0928 \mathrm{x}+9,4831$ & $0,898 * *$ \\
\hline \multirow{3}{*}{ IAC Imperador } & $\mathrm{y}_{0}=-0,000046 x^{2}+0,0834 \mathrm{x}+10,5987$ & $0,856^{* *}$ \\
\hline & $\mathrm{y}_{4}=-0,000052 \mathrm{x}^{2}+0,0943 \mathrm{x}+8,8211$ & $0,913 * *$ \\
\hline & $\mathrm{y}_{8}=-0,000051 \mathrm{x}^{2}+0,0930 \mathrm{x}+7,9176$ & $0,917 * *$ \\
\hline \multirow{3}{*}{ IAC Milênio } & $\mathrm{y}_{0}=-0,000044 \mathrm{x}^{2}+0,0792 \mathrm{x}+11,5989$ & $0,812 * *$ \\
\hline & $\mathrm{y}_{4}=-0,000053 \mathrm{x}^{2}+0,0942 \mathrm{x}+10,3096$ & $0,877 * *$ \\
\hline & $\mathrm{y}_{8}=-0,000047 \mathrm{x}^{2}+0,0876 \mathrm{x}+8,8995$ & $0,899 * *$ \\
\hline \multirow{3}{*}{ IPR Andorinha } & $\mathrm{y}_{0}=-0,000043 \mathrm{x}^{2}+0,0791 \mathrm{x}+11,1376$ & $0,838 * *$ \\
\hline & $\mathrm{y}_{4}=-0,000052 \mathrm{x}^{2}+0,0967 \mathrm{x}+6,3380$ & $0,949 * *$ \\
\hline & $y_{8}=-0,000049 x^{2}+0,0905 x+8,6234$ & $0,909 * *$ \\
\hline \multirow{3}{*}{ IPR Campos Gerais } & $\mathrm{y}_{0}=-0,000044 \mathrm{x}^{2}+0,0797 \mathrm{x}+11,5506$ & $0,825 * *$ \\
\hline & $\mathrm{y}_{4}=-0,000054 \mathrm{x}^{2}+0,0992 \mathrm{x}+6,7523$ & $0,942 * *$ \\
\hline & $\mathrm{y}_{8}=-0,000052 \mathrm{x}^{2}+0,0948 \mathrm{x}+7,7286$ & $0,925 * *$ \\
\hline \multirow{3}{*}{ IPR 139} & $\mathrm{y}_{0}=-0,000048 \mathrm{x}^{2}+0,0896 \mathrm{x}+8,1592$ & $0,920 * *$ \\
\hline & $\mathrm{y}_{4}=-0,000047 \mathrm{x}^{2}+0,0883 \mathrm{x}+8,1519$ & $0,918 * *$ \\
\hline & $\mathrm{y}_{8}=-0,000048 \mathrm{x}^{2}+0,0910 \mathrm{x}+5,9940$ & $0,951 * *$ \\
\hline \multirow{3}{*}{ IPR Tangará } & $\mathrm{y}_{0}=-0,000049 x^{2}+0,0900 x+8,9602$ & $0,896 * *$ \\
\hline & $\mathrm{y}_{4}=-0,000054 \mathrm{x}^{2}+0,0992 \mathrm{x}+8,4648$ & $0,924 * *$ \\
\hline & $\mathrm{y}_{8}=-0,000055 \mathrm{x}^{2}+0,1017 x+6,3771$ & $0,949 * *$ \\
\hline \multirow{3}{*}{ Bola Cheia } & $\mathrm{y}_{0}=-0,000045 \mathrm{x}^{2}+0,0822 \mathrm{x}+10,9346$ & $0,844 * *$ \\
\hline & $\mathrm{y}_{4}=-0,000051 \mathrm{x}^{2}+0,0941 \mathrm{x}+8,1038$ & $0,927 * *$ \\
\hline & $\mathrm{y}_{8}=-0,000052 \mathrm{x}^{2}+0,0971 \mathrm{x}+7,1025$ & $0,937 * *$ \\
\hline
\end{tabular}

${ }^{1} \mathrm{x}=$ tempo para hidratação (horas) e $\mathrm{y}=$ quantidade de água absorvida $(\mathrm{mL}) . * *=$ significativo pelo teste $\mathrm{t}$ ao nível de $1 \%$ de probabilidade. ${ }^{l} x=$ time for maximum hydration (hours) and $y=$ amount of water absorbed $(m L) . * *=$ Significant byt test at $1 \%$ probability level.

Fonte: Autoria própria. Own authorship. 
Houve diferença significativa entre os tempos de armazenamento, sendo que quanto maior o tempo de armazenamento, maior foi o tempo para máxima hidratação, que aumentou 16 minutos em relação aos grãos recém colhidos. Ramos Junior, Lemos e Silva (2005a), relataram que, apesar das cultivares apresentarem menores tempos para máxima hidratação, após seis meses de armazenamento este tempo variou em 1 hora. Entretanto, mesmo ocorrendo diferenças entre os tempos de armazenamento, as cultivares apresentaram desempenho satisfatório com tempo para máxima hidratação menor que 16 horas, estando de acordo com a metodologia utilizada (BRASIL, 2006).

Os componentes da cor do tegumento (Luminosidade (L), a, b e Cromaticidade (C)) das cultivares apresentaram diferença significativa durante o armazenamento (Tabela 3). Para os grãos de feijão do grupo comercial carioca, o valor de L ideal é acima de 55, representando coloração clara, característica desejada pelo consumidor (RIBEIRO et al., 2008). Apesar do escurecimento aos 4 meses de armazenamento, a cultivar BRSMG Madrepérola foi a que manteve os valores de L mais próximos do ideal, apresentando L de 55,73, 54,23 e 53,89 aos 0, 4 e 8 meses após o armazenamento, respectivamente. Esta característica de resistência ao escurecimento é intrínseca à cultivar (CARNEIRO et al., 2012; SIQUEIRA et al., 2014), sendo que, cultivares que apresentam estas características de coloração clara prolongada durante o armazenamento são visadas pelos melhoristas como fonte de genes buscando essa característica em novos cultivares.

Em trabalhos realizados com a cultivar BRS Pérola, que é a mais utilizada no Brasil, foi verificada diminuição do valor da luminosidade durante o armazenamento (Tabela 3). Oliveira et al. (2011) verificaram com seis meses de armazenamento refrigerado e sem embalagem, queda de $12 \%$ no valor de L, o mesmo resultado encontrado neste trabalho para a cultivar BRS Pérola. Lima, Tomé e Abreu (2014) observaram diminuição de 15\% aos seis meses de armazenamento em embalagem comercial.

A cultivar IAC Imperador apresentou maiores valores para variável "a" em todos os períodos de armazenamento, demonstrando que esta possui o tegumento mais avermelhado em comparação aos outros cultivares, e que a cor se intensificou ao longo do tempo, o que pode ser observado pelo aumento do valor de C. Já a IPR Andorinha apresentou maiores valores de "b", evidenciando a cor do tegumento mais amarelada, que também se intensificou ao longo do tempo de armazenamento (Tabela 3).

As cultivares apresentaram queda nos teores de proteína bruta dos grãos durante o armazenamento (Tabela 4). O teor de proteína variou entre 21,8\% e 15,4\%. Esta queda demonstra que o valor nutricional não foi preservado. No entanto, Oliveira et al. (2011), que realizou o armazenamento em câmara fria, observaram que as cultivares do grupo comercial preto e carioca apresentaram seus teores conservados durante seis meses.

A cultivar IAC Alvorada manteve seu teor de proteína bruta durante os 4 meses de armazenamento (20,7\%), e aos 8 meses este teor reduziu para 16,8\%. A BRSMG Majestoso, IAC Milênio, IPR 139 e IPR Tangará apresentaram maiores valores quando recém colhidas e após oito meses, mostrando que estas cultivares manteve o seu valor nutricional. Quanto ao comportamento das cultivares em cada período de armazenamento, observou-se que as 
cultivares recém colhidas apresentaram em média $20 \%$ de proteína bruta, corroborando com Farinelli e Lemos (2010), Perina et al. (2010) e Mingotte et al. (2013).

Tabela 3. Desdobramento da interação entre cultivares e o armazenamento dos grãos para cor do tegumento, 2014. Jaboticabal, $\mathrm{SP}^{(1)}$. Partioning of interaction between cultivars and grain storage for tegument color, 2014. Jaboticabal, $S P^{(1)}$.

\begin{tabular}{|c|c|c|c|c|c|c|}
\hline \multirow{3}{*}{ Cultivares } & \multicolumn{6}{|c|}{ Armazenamento (meses) } \\
\hline & 0 & 4 & 8 & 0 & 4 & 8 \\
\hline & \multicolumn{3}{|c|}{$\mathrm{L}$} & \multicolumn{3}{|c|}{$\mathrm{a}$} \\
\hline BRS Pérola & $50,38 \mathrm{Ac}$ & $44,87 \mathrm{Be}$ & $44,20 \mathrm{Be}$ & $9,58 \mathrm{Cb}$ & $11,83 \mathrm{Ba}$ & $13,00 \mathrm{Aa}$ \\
\hline BRS Estilo & $52,39 \mathrm{Ab}$ & $45,60 \mathrm{Bd}$ & $44,12 \mathrm{Ce}$ & $9,61 \mathrm{Cb}$ & $11,28 \mathrm{Bb}$ & $12,33 \mathrm{Ac}$ \\
\hline BRSMG Madrepérola & $55,73 \mathrm{Aa}$ & $54,23 \mathrm{Ba}$ & $53,89 \mathrm{Ba}$ & $6,65 \mathrm{Ce}$ & 7,32 Be & 7,85 Ae \\
\hline BRSMG Majestoso & $50,36 \mathrm{Ac}$ & $44,30 \mathrm{Be}$ & $43,51 \mathrm{Be}$ & $9,01 \mathrm{Cc}$ & $11,35 \mathrm{Bb}$ & $12,56 \mathrm{Ab}$ \\
\hline IAC Alvorada & $51,64 \mathrm{Ab}$ & $47,60 \mathrm{Bb}$ & $47,08 \mathrm{Bb}$ & $8,88 \mathrm{Cc}$ & $10,23 \mathrm{Bc}$ & $11,72 \mathrm{Ad}$ \\
\hline IAC Formoso & $51,62 \mathrm{Ab}$ & $46,96 \mathrm{Bb}$ & $47,49 \mathrm{Bb}$ & $8,97 \mathrm{Cc}$ & $10,23 \mathrm{Bd}$ & $11,29 \mathrm{Ad}$ \\
\hline IAC Imperador & $50,74 \mathrm{Ac}$ & $45,76 \mathrm{Bd}$ & $45,14 \mathrm{Bd}$ & $10,36 \mathrm{Ca}$ & $11,67 \mathrm{Ba}$ & $13,40 \mathrm{Aa}$ \\
\hline IAC Milênio & $50,80 \mathrm{Ac}$ & $46,77 \mathrm{Bb}$ & $46,58 \mathrm{Bb}$ & $9,27 \mathrm{Cb}$ & $11,17 \mathrm{Bb}$ & $13,14 \mathrm{Aa}$ \\
\hline IPR Andorinha & 48,27 Ae & $45,51 \mathrm{Bd}$ & $44,64 \mathrm{Bd}$ & $10,37 \mathrm{Ca}$ & $11,47 \mathrm{Bb}$ & $13,23 \mathrm{Aa}$ \\
\hline IPR Campos Gerais & $50,26 \mathrm{Ac}$ & $46,13 \mathrm{Bc}$ & $46,12 \mathrm{Bc}$ & $8,40 \mathrm{Cd}$ & $10,01 \mathrm{Bd}$ & $11,41 \mathrm{Ad}$ \\
\hline IPR 139 & 49,29 Ad & $45,75 \mathrm{Bd}$ & $45,47 \mathrm{Bd}$ & $10,07 \mathrm{Ca}$ & $10,64 \mathrm{Bc}$ & $12,74 \mathrm{Ab}$ \\
\hline IPR Tangará & $50,02 \mathrm{Ac}$ & $46,66 \mathrm{Bb}$ & $46,70 \mathrm{Bb}$ & $9,32 \mathrm{Cb}$ & $10,53 \mathrm{Bc}$ & $12,27 \mathrm{Ac}$ \\
\hline Bola Cheia & $50,50 \mathrm{Ac}$ & $46,12 \mathrm{Bc}$ & $45,84 \mathrm{Bc}$ & $9,23 \mathrm{Cb}$ & $10,50 \mathrm{Bc}$ & $12,32 \mathrm{Ac}$ \\
\hline Média & $50,92 \mathrm{~A}$ & 46,64 B & $46,22 \mathrm{C}$ & $9,21 \mathrm{C}$ & 10,63 B & $12,10 \mathrm{~A}$ \\
\hline \multirow[t]{2}{*}{ Teste F } & $30,99 * *$ & $58,41 * *$ & $66,55^{* *}$ & $51,83 * *$ & $75,42 * *$ & $116,58 * *$ \\
\hline & \multicolumn{6}{|c|}{ Armazenamento (meses) } \\
\hline \multirow[t]{2}{*}{ Cultivares } & 0 & 4 & 8 & 0 & 4 & 8 \\
\hline & \multicolumn{3}{|c|}{ b } & \multicolumn{3}{|c|}{$\mathrm{C}$} \\
\hline BRS Pérola & $15,56 \mathrm{Cc}$ & $16,78 \mathrm{Bb}$ & $17,80 \mathrm{Ac}$ & $18,27 \mathrm{Cb}$ & $20,53 \mathrm{Ba}$ & $22,04 \mathrm{Ac}$ \\
\hline BRS Estilo & $15,76 \mathrm{Bc}$ & $16,09 \mathrm{Bc}$ & $17,04 \mathrm{Ad}$ & $18,46 \mathrm{Cb}$ & $19,65 \mathrm{Bb}$ & $21,03 \mathrm{Ad}$ \\
\hline BRSMG Madrepérola & $15,41 \mathrm{Bc}$ & $16,56 \mathrm{Ab}$ & $17,08 \mathrm{Ad}$ & $16,79 \mathrm{Cd}$ & $18,10 \mathrm{Bd}$ & 18,80 Ae \\
\hline BRSMG Majestoso & $15,14 \mathrm{Cd}$ & $16,34 \mathrm{Bb}$ & $18,01 \mathrm{Ac}$ & $17,62 \mathrm{Cc}$ & $19,89 \mathrm{Bb}$ & $21,96 \mathrm{Ac}$ \\
\hline IAC Alvorada & $15,14 \mathrm{Cd}$ & $15,88 \mathrm{Bc}$ & $18,07 \mathrm{Ac}$ & $17,56 \mathrm{Cc}$ & $18,89 \mathrm{Bc}$ & $21,54 \mathrm{Ac}$ \\
\hline IAC Formoso & $15,32 \mathrm{Cc}$ & $15,93 \mathrm{Bc}$ & $17,91 \mathrm{Ac}$ & $17,75 \mathrm{Cc}$ & $18,93 \mathrm{Bc}$ & $21,17 \mathrm{Ad}$ \\
\hline IAC Imperador & $16,84 \mathrm{Bb}$ & $16,60 \mathrm{Bb}$ & $18,88 \mathrm{Ab}$ & $19,77 \mathrm{Ba}$ & $20,29 \mathrm{Ba}$ & $23,15 \mathrm{Aa}$ \\
\hline IAC Milênio & $15,91 \mathrm{Cc}$ & $16,58 \mathrm{Bb}$ & $19,24 \mathrm{Aa}$ & $18,41 \mathrm{Cb}$ & $19,99 \mathrm{Bb}$ & $23,30 \mathrm{Aa}$ \\
\hline IPR Andorinha & $17,49 \mathrm{Ba}$ & $17,37 \mathrm{Ba}$ & $19,44 \mathrm{Aa}$ & $20,34 \mathrm{Ba}$ & $20,82 \mathrm{Ba}$ & $23,51 \mathrm{Aa}$ \\
\hline IPR Campos Gerais & $14,68 \mathrm{Cd}$ & $15,40 \mathrm{Bd}$ & $17,37 \mathrm{Ad}$ & $16,91 \mathrm{Cd}$ & $18,37 \mathrm{Bd}$ & $20,78 \mathrm{Ad}$ \\
\hline IPR 139 & $17,44 \mathrm{Ba}$ & $16,09 \mathrm{Cc}$ & $18,66 \mathrm{Ab}$ & $20,14 \mathrm{Ba}$ & $19,29 \mathrm{Cc}$ & $22,60 \mathrm{Ab}$ \\
\hline IPR Tangará & $15,52 \mathrm{Bc}$ & $15,82 \mathrm{Bc}$ & $18,45 \mathrm{Ab}$ & $18,10 \mathrm{Cb}$ & $19,00 \mathrm{Bc}$ & $22,15 \mathrm{Ac}$ \\
\hline Bola Cheia & $15,48 \mathrm{Bc}$ & $15,45 \mathrm{Bd}$ & $18,04 \mathrm{Ac}$ & $18,02 \mathrm{Cb}$ & $18,69 \mathrm{Bc}$ & $21,85 \mathrm{Ac}$ \\
\hline Média & $15,82 \mathrm{C}$ & $16,22 \mathrm{~B}$ & $18,15 \mathrm{~A}$ & $18,32 \mathrm{C}$ & $19,42 \mathrm{~B}$ & $21,84 \mathrm{~A}$ \\
\hline Teste $\mathrm{F}$ & $19,23 * *$ & $7,56 * *$ & $14,16^{* *}$ & $26,20 * *$ & $14,71 * *$ & $32,25 * *$ \\
\hline
\end{tabular}

(1) Médias seguidas pela mesma letra maiúscula na linha e minúscula na coluna não diferem estatisticamente pelo teste de Scott e Knott $(\mathrm{P}<0,05)$. **Significativo a $1 \%$ de probabilidade. L: Luminosidade, a: Intensidade de cor do verde ao vermelho, b: intensidade de cor do azul ao amarelo, C: croma. ${ }^{(1)}$ Means followed by the same capital letter on the line and lower case in the column do not differ statistically by Scott Knott teste $(P<0.05)$. ** Significant at 1\% probability. L: Luminosity, $a=$ Color intensity from green to red, $b$ : Color intensity from blue to yellow, C: chroma.

Fonte: Autoria própria. Own authorship. 
Após quatro meses de armazenamento, as cultivares IAC Alvorada e IAC Formoso apresentaram valores acima de $20 \%$ de proteína, sendo os únicos cultivares a manter esse atributo qualitativo em condições ambientais. Após oito meses, o teor médio de proteína bruta diminuiu para 17,5\%, com menor porcentagem obtido pelos grãos do cultivar IPR Andorinha, diferindo significativamente das demais.

Tabela 4. Desdobramento da interação entre cultivares e o armazenamento dos grãos para teor de proteína bruta (\%), 2014. Jaboticabal, SP ${ }^{(1)}$. Development of interaction between cultivars and grain storage for crude protein content (\%), 2014. Jaboticabal, $S P^{(1)}$.

\begin{tabular}{lccc}
\hline \multirow{2}{*}{ Cultivares } & \multicolumn{3}{c}{ Armazenamento (meses) } \\
\cline { 2 - 4 } & 0 & 4 & 8 \\
\hline BRS Pérola & $19,1 \mathrm{Ab}$ & $18,3 \mathrm{Ac}$ & $16,8 \mathrm{Bb}$ \\
BRS Estilo & $19,9 \mathrm{Ab}$ & $19,1 \mathrm{Ac}$ & $18,0 \mathrm{Ba}$ \\
BRSMG Madrepérola & $20,3 \mathrm{Ab}$ & $19,5 \mathrm{Ab}$ & $17,5 \mathrm{Ba}$ \\
BRSMG Majestoso & $20,7 \mathrm{Aa}$ & $18,4 \mathrm{Bc}$ & $18,3 \mathrm{Ba}$ \\
IAC Alvorada & $20,7 \mathrm{Aa}$ & $20,7 \mathrm{Aa}$ & $16,8 \mathrm{Bb}$ \\
IAC Formoso & $19,9 \mathrm{Ab}$ & $20,7 \mathrm{Aa}$ & $17,7 \mathrm{Ba}$ \\
IAC Imperador & $20,2 \mathrm{Ab}$ & $19,6 \mathrm{Ab}$ & $17,3 \mathrm{Bb}$ \\
IAC Milênio & $21,8 \mathrm{Aa}$ & $19,8 \mathrm{Bb}$ & $18,4 \mathrm{Ca}$ \\
IPR Andorinha & $20,3 \mathrm{Ab}$ & $17,5 \mathrm{Bd}$ & $15,4 \mathrm{Cc}$ \\
IPR Campos Gerais & $19,0 \mathrm{Ab}$ & $17,4 \mathrm{Bd}$ & $17,0 \mathrm{Bb}$ \\
IPR 139 & $21,2 \mathrm{Aa}$ & $18,4 \mathrm{Bc}$ & $18,7 \mathrm{Ba}$ \\
IPR Tangará & $20,8 \mathrm{Aa}$ & $18,8 \mathrm{Bc}$ & $17,8 \mathrm{Ba}$ \\
Bola Cheia & $20,1 \mathrm{Ab}$ & $18,3 \mathrm{Bc}$ & $17,8 \mathrm{Ba}$ \\
\hline Média & $20,3 \mathrm{~A}$ & $19,0 \mathrm{~B}$ & $17,5 \mathrm{C}$ \\
\hline Teste F & $3,61^{* *}$ & $9,32^{* *}$ & $4,62 * *$ \\
\hline
\end{tabular}

(1) Médias seguidas pela mesma letra maiúscula linha na e minúscula coluna na não diferem estatisticamente pelo teste de Scott e Knott $(\mathrm{P}<0,05)$. **Significativo a $1 \%$ de probabilidade. ${ }^{(1)}$ Means followed by the same capital letter on the line and lower case in the column do not differ statistically by Scott Knott teste $(P<0.05)$. ** Significant at $1 \%$ probability.

Fonte: Autoria própria. Own authorship.

O teor de proteína está ligado a fatores como: condições de armazenamento dos grãos, quanto maior a temperatura, mais rápido ocorre a desnaturação da proteína reduzindo seu teor nos grãos; diferença de cultivares e local de produção. Em trabalho de Santos, Menezes e Villela (2005), com cultivares de feijão preto, produzidos e armazenados em Santa Maria RS, o teor proteico dos grãos não sofreram redução após oito meses de armazenamento. Verifica-se, portanto, que as condições de temperatura e umidade do ar mais elevadas em Jaboticabal-SP (Figura 1) podem ter desfavorecido a manutenção do teor proteico dos grãos de feijão.

O tempo de cozimento aumentou ao longo do tempo de armazenamento para todas as cultivares estudadas (Tabela 5). De acordo com a escala de nível de resistência ao cozimento de Proctor e Watts (1987), os grãos passaram de resistência normal ao cozimento (23 minutos), para resistência média (31 minutos) após oito meses de armazenamento. 
Em geral, o tempo de cozimento foi influenciado pelas cultivares, o que corrobora com os resultados apresentados por Ramos Junior, Lemos e Silva (2005b), Farinelli e Lemos (2010), Araújo et al. (2012) e Oliveira et al. (2013), e pelo tempo de armazenamento, como encontrado por Arruda et al. (2012), Morais et al. (2010), Ramos Junior, Lemos e Silva (2005a) e Oliveira et al. (2011).

As cultivares IAC Alvorada, IAC Formoso e IPR Andorinha, após oito meses de armazenamento, apresentaram 27, 29 e 26 minutos, respectivamente, e estão dentro do limite preconizado como aceitável por Ramalho e Abreu (2006), que é inferior a 30 minutos. Vale ressaltar que a IPR Andorinha, mesmo não apresentando menor tempo quando recém colhido e aos quatro meses, se sobressaiu com menor tempo de cozimento aos oito meses e apresentou menor variação durante período de armazenamento. A cultivar IAC Alvorada merece destaque, pois apresentou o menor tempo quando recém colhida e após oito meses de armazenamento. Com exceção da BRSMG Madrepérola e IPR Campos Gerais, todas as cultivares apresentaram tempo de cozimento abaixo de 30 minutos aos 4 meses de armazenamento, demonstrando que este período não prejudica a aceitabilidade quanto a esta característica.

Tabela 5. Desdobramento da interação entre cultivares e o armazenamento dos grãos para tempo de cozimento (minutos), 2014. Jaboticabal, SP ${ }^{(1)}$. Partioning of interaction between cultivars and grain storage for cooking time (minutes), 2014. Jaboticabal, SP(1).

\begin{tabular}{|c|c|c|c|c|}
\hline \multirow{2}{*}{ Cultivares } & \multicolumn{3}{|c|}{ Armazenamento (meses) } & \multirow{2}{*}{$\begin{array}{c}\tilde{A}^{(2)} \\
---(\min .)---\end{array}$} \\
\hline & 0 & 4 & 8 & \\
\hline BRS Pérola & $22 \mathrm{Bd}$ & $22 \mathrm{Be}$ & $30 \mathrm{Ad}$ & 7 \\
\hline BRS Estilo & $23 \mathrm{Cd}$ & $26 \mathrm{Bd}$ & $34 \mathrm{Ab}$ & 11 \\
\hline BRSMG Madrepérola & $22 \mathrm{Bd}$ & $35 \mathrm{Aa}$ & $36 \mathrm{Aa}$ & 14 \\
\hline BRSMG Majestoso & $24 \mathrm{Cc}$ & $29 \mathrm{Bc}$ & $34 \mathrm{Ab}$ & 9 \\
\hline IAC Alvorada & $19 \mathrm{Cf}$ & $26 \mathrm{Bd}$ & 27 Af & 9 \\
\hline IAC Formoso & $19 \mathrm{Bf}$ & $29 \mathrm{Ac}$ & $29 \mathrm{Ae}$ & 10 \\
\hline IAC Imperador & $20 \mathrm{Ce}$ & $25 \mathrm{Bd}$ & $30 \mathrm{Ad}$ & 10 \\
\hline IAC Milênio & $28 \mathrm{Ba}$ & $29 \mathrm{Bc}$ & $31 \mathrm{Ad}$ & 3 \\
\hline IPR Andorinha & $23 \mathrm{Bd}$ & $26 \mathrm{Ad}$ & 26 Af & 3 \\
\hline IPR Campos Gerais & $22 \mathrm{Bd}$ & $32 \mathrm{Ab}$ & $32 \mathrm{Ac}$ & 10 \\
\hline IPR 139 & $26 \mathrm{Bb}$ & $26 \mathrm{Bd}$ & $32 \mathrm{Ac}$ & 6 \\
\hline IPR Tangará & $22 \mathrm{Cd}$ & $25 \mathrm{Bd}$ & $33 \mathrm{Ac}$ & 11 \\
\hline Bola Cheia & $23 \mathrm{Cd}$ & $28 \mathrm{Ba}$ & $34 \mathrm{Ab}$ & 11 \\
\hline Média & 23 & 27 & 31 & 9 \\
\hline Teste F & $34,07 * *$ & $57,09 * *$ & $42,26^{* *}$ & - \\
\hline \multicolumn{5}{|c|}{$\begin{array}{l}\text { (1) Médias seguidas pela mesma letra maiúscula na linha e minúscula na coluna diferem estatisticamente pelo } \\
\text { teste de Scott e Knott }(\mathrm{P}<0,05) .{ }^{*} \text { Significativo a } 1 \% \text { de probabilidade. }{ }^{2} \tilde{\mathrm{A}}=\text { intervalo entre recém colhido e oito } \\
\text { meses de armazenamento. }{ }^{(1)} \text { Means followed by the same capital letter on the line and lower case in the column } \\
\text { do not differ statistically by Scott Knott teste }(P<0.05) . * * \text { Significant at } 1 \% \text { probability. }{ }^{2} \tilde{A}=\text { Interval between } \\
\text { freshly harvested and eight months of storage. } \\
\text { Fonte: Autoria própria. Own authorship. }\end{array}$} \\
\hline
\end{tabular}


Vale ressaltar que as cultivares apresentaram escurecimento dos grãos (Tabela 3), o que é associado pelo consumidor com qualidade inferior dos grãos e maior tempo de cozimento (OLIVEIRA et al., 2011). Todavia, esta associação é controversa, uma vez que os resultados encontrados neste trabalho demonstram que nem sempre o escurecimento dos grãos está associado com maior tempo de cozimento.

\section{CONCLUSÃO}

O período de armazenamento não altera significativamente os atributos qualitativos dos grãos, mantendo a maioria das características essenciais ao mercado consumidor.

A BRSMG Madrepérola manteve a cor do tegumento e o menor tempo de cozimento. Houve destaque para a IPR Andorinha, que demonstrou que o escurecimento dos grãos de feijão não está associado com o tempo de cozimento.

Todas as cultivares apresentaram resultados satisfatórios para o tempo de máxima hidratação e a relação de hidratação.

\section{AGRADECIMENTOS}

À Coordenação de Aperfeiçoamento de Pessoal de Nível Superior (CAPES), pela concessão de bolsa de estudo de mestrado.

Ao Laboratório de Fitoquímica do Centro de Pesquisa e Desenvolvimento de Recursos Genéticos Vegetais do Instituto Agronômico - IAC, pelo auxílio na análise de colorimetria.

\section{REFERÊNCIAS BIBLIOGRÁFICAS}

ARAÚJO, A. L. C.; RAMAlHO, M. A. P.; ABREU, A. F. B. Estimates of genetic parameters of late seed-coat darkening of carioca type dry beans. Ciência e Agrotecnologia, Lavras, v. 36, n. 2, p.156-162, 2012. Disponível em: http://dx.doi.org/10.1590/S141370542012000200003. Acesso em: 09 jul. 2018.

ARRUDA, B.; GUIDOLIN, A. F.; COIMBRA, J. L. M.; BATTILANA, J. Environmental is crucial to the cooking time of beans. Ciência e Tecnologia de Alimentos, Campinas, v. 32, n. 3, p.573-578, 2012. Disponível em: http://dx.doi.org/10.1590/S0101-20612012005000078. Acesso em: 21 ago. 2018.

BOURNE, M. C. Size, density, and hardshell in dry beans. Food Technology, Chicago, v. 21, n. 12, p.335-398, 1967.

BRASIL. Instrução Normativa $n^{\circ}$ 25, de 23 de maio de 2006. Estabelece os critérios mínimos a serem observados para a determinação do valor de cultivo e uso - VCU de feijão e os respectivos formulários anexos para inscrição de cultivares no Registro Nacional de Cultivares. Anexo I. Requisitos mínimos para determinação do valor de cultivo e uso de feijão (Phaseolus vulgaris) para a inscrição no Registro Nacional de Cultivares - RNC. Diário Oficial [da] República Federativa do Brasil, Brasília, 19 jun. 2006. Seção 1, p.16. 
BRASIL. Ministério da Agricultura, Pecuária e Abastecimento - MAPA. Registro Nacional de Cultivares - RNC. Brasília, 2016. Disponível em: http://extranet.agricultura.gov.br/php/snpc/cultivarweb/cultivares_registradas.php. Acesso em: 09 jul. 2018.

BURATTO, J. S.; MODA-CIRINO, V.; SCHOLZ, M. B. S.; LANGAME, D. E. M.; FONSECA JÚNIOR, N.; PRETE, C. E. C. Variabilidade genética e efeito do ambiente para o teor de proteína em grãos de feijão. Acta Scientiarum. Agronomy, Maringá, v. 31, n. 4, p.593-597, 2009. Disponível em: http://dx.doi.org/10.4025/actasciagron.v31i4.910. Acesso em: 21 ago. 2018.

CARbOnEll, S. A. M.; CHIORATO, A. F.; GONÇAlVES, J. G. R.; PERINA, E. F.; CARVALHO, C. R. L. Tamanho de grão comercial em cultivares de feijoeiro. Ciência Rural, Santa Maria, v. 40, n. 10, p.2067-2073, 2010. Disponível em: http://dx.doi.org/10.1590/S0103-84782010005000159. Acesso em: 09 jul. 2018.

CARNEIRO, J. E. S.; ABREU, A. F. B; RAMALHO, M. A. P.; PAULA JUNIOR, T. J.; DEL PELOSO, M. J.; MELO, L. C.; PEREIRA, H. S.; PEREIRA FILHO, I. A.; MARTINS, M.; VIEIRA, R. F.; MARTINS, F. A. D.; COELHO, M. A. O.; CARNEIRO, P. C. S.; MOREIRA, J. A. A.; SANTOS, J. B.; FARIA, L.C.; COSTA, J. G. C.; TEIXEIRA, H. BRSMG Madrepérola: common bean cultivar with late-darkening Carioca grain. Crop Breeding and Applied Biotechnology, Viçosa, v. 12, n. 4, p.281-284, 2012. Disponível em: http://dx.doi.org/10.1590/S1984-70332012000400008. Acesso em: 15 jul. 2018.

COELHO, C. M. M.; SOUZA, C. A.; DANELli, A. L. D.; PEREIRA, T.; SANTOS, J. C. P.; PIAZZOLI, D. Capacidade de cocção de grãos de feijão em função do genótipo e da temperatura da água de hidratação. Ciência e Agrotecnologia, Lavras, v. 32, n. 4, p.810801086, 2008. Disponível em: http://dx.doi.org/10.1590/S1413-70542008000400007. Acesso em: 21 ago. 2018.

ESTEVES, A. M.; ABREU, C. M. P.; SANTOS, C. D. dos; CORRÊA, A. D. Comparação química e enzimática de seis linhagens de feijão (Phaseolus vulgaris L.). Ciência e Agrotecnologia, Lavras, v. 26, n. 5, p.999-1005, 2002. Disponível em: http://www.dieteticai.ufba.br/Temas/metodosdecoccao/para\%20a\%20aula\%20de\%20metodos $\% 20$ de\%20coccao.pdf. Acesso em: 18 set. 2019.

FARINELLI, R.; LEMOS, L. B. Qualidade nutricional e tecnológica de genótipos de feijão cultivados em diferentes safras agrícolas. Bragantia, Campinas, v. 69, n. 3, p.759-764, 2010. Disponível em: http://dx.doi.org/10.1590/S0006-87052010000300030. Acesso em: 15 jul. 2018.

LIMA, R. A. Z.; TOMÉ, L. M.; ABREU, C. M. P. de. Embalagem a vácuo: efeito no escurecimento e endurecimento do feijão durante o armazenamento. Ciência Rural, Santa Maria, v. 44, n. 9, p.1664-1670, 2014. Disponível em: http://dx.doi.org/10.1590/01038478cr20120832. Acesso em: 17 jul. 2018.

MINGOTTE, F. L. C.; GUARNIERI, C. C.; FARINELLI, R.; LEMOS, L. B. Desempenho produtivo e qualidade pós-colheita de genótipos de feijão do grupo comercial carioca 
cultivados na época de inverno-primavera. Bioscience Journal, Uberlândia, v. 29, n. 5, p.1101-1110, 2013.

MORAIS, P. P. P.; VALENTINI, G.; GUIDOLIN, A. F.; BALDISSERA, J. N. C.; COIMBRA, J. L. M. Influência do período e das condições de armazenamento de feijão no tempo de cocção. Revista Ciência Agronômica, v. 41. n. 4, p.593-598, 2010. Disponível em: https://dx.doi.org/10.1590/S1806-66902010000400011. Acesso em: 21 ago. 2018.

NASAR-ABBAS, S. M.; PLUMMER, J. A.; SIDDIQUE, K. H. M.; WHITE, P.; HARRIS, D.; DODS, K. Nitrogen retards and oxygen accelerates colour darkening in faba bean (Vicia faba L.) during storage. Postharvest Biology and Technology, Amsterdam, v. 47, n. 3, p.113-118, 2008. Disponível em: http://dx.doi.org/10.1016/j.postharvbio.2007.06.007. Acesso em: 17 jul. 2018.

OLIVEIRA, V. R.; RIBEIRO, N. D.; MAZIERO, S. R.; CARGNELUTTI FILHO, A.; JUST, E. Qualidade para o cozimento e composição nutricional de genótipos de feijão com e sem armazenamento sob refrigeração. Ciência Rural, Santa Maria, v. 41, n. 5, p.746-752, 2011. Disponível em: http://dx.doi.org/10.1590/S0103-84782011005000050. Acesso em: 15 jul. 2018.

OLIVEIRA, V. R.; RIBEIRO, N. D.; JOST, E.; COLPO, E.; POERSCH, N. L. Perfil sensorial de cultivares de feijão sob diferentes tempos de cozimento. Alimentos e Nutrição, Araraquara, v. 24, n. 2, p.145-152, 2013.

PERINA, E. F.; CARVAlho, C. R. L.; CHIORATO, A. F.; GONÇAlveS, J. G. R.; CARBONELL, S. A. M. Avaliação da estabilidade e adaptabilidade de genótipos de feijoeiro (Phaseolus vulgaris L.) baseada na análise multivariada da "performance" genotípica. Ciência e Agrotecnologia, Lavras, v. 34, n. 2, p.398-406, 2010. Disponível em: http://dx.doi.org/10.1590/S1413-70542010000200018. Acesso em: 09 jul. 2018.

PERINA, E. F.; CARVAlHO, C. R. L.; CHIORATO, A. F.; LOPES, R. L. T; GONÇALVES, J. G. R.; CARBONELL, S. A. M. Technological quality of common bean grains obtained in different growing seasons. Bragantia, Campinas, v. 73, n. 1, p.14-22, 2014. Disponível em: http://dx.doi.org/10.1590/brag.2014.008. Acesso em: 17 jul. 2018.

PROCTOR, J. R.; WATTS, B. M. Development of a modifi ed Mattson Bean Cooker procedure based on sensory panel cookability evaluation. Canadian Institute of Food Science and Technology Journal, Toronto, v. 20, n. 1, p.9-14, 1987. Disponível em: http://dx.doi.org/10.1016/S0315-5463(87)70662-2. Acesso em: 21 ago. 2018.

RAMALHO, M.A.P.; ABREU, A. F. B. Cultivares. In: VIEIRA, C.; PAULA JUNIOR, T. J. P.; BORÉM, A. (ed.). Feijão. 2. ed. Viçosa: UFV, 2006. cap. 14, p. 415-436.

RAMOS JUNIOR, E. U.; LEMOS, L. B.; SILVA, T. R. B. Características tecnológicas de cultivares de feijão antes e após o armazenamento. Revista Brasileira de Armazenamento, Viçosa, v. 30, n. 1, p.97-103, 2005a.

RAMOS JUNIOR, E. U.; LEMOS, L. B.; SILVA, T. R. B. Componentes da produção, produtividade de grãos e características tecnológicas de cultivares de feijão. Bragantia, 
Campinas, v. 64, n. 1, p.75-82, 2005b. Disponível em: http://dx.doi.org/10.1590/S000687052005000100008. Acesso em: 02 set. 2018.

RIBEIRO, N. D.; STORCK, L. Genitores potenciais para hibridações identificados por divergência genética em feijão carioca. Ciência Rural, Santa Maria, v. 33, n. 3, p.413-421, 2003.

RIBEIRO, N. D.; STORCK, L.; POERSCH, N. L. Classificação de lotes comerciais de feijão por meio da claridade do tegumento dos grãos. Ciência Rural, Santa Maria, v. 38, n. 7, p.2042-2045, 2008.

SANTOS, C. M. R.; MENEZES, N. L.; VILLELA, F. A. Modificações fisiológicas e bioquímicas em sementes de feijão no armazenamento. Revista Brasileira de Sementes, Londrina, v. 27, n. 1, p.104-114, 2005. Disponível em: http://dx.doi.org/10.1590/S010131222005000100013. Acesso em: 02 set. 2018.

SIQUEIRA, S. B.; PEREIRA, W. J.; BATISTA, K. A.; OOMAH B. D.; FERNANDES, K. F.; BASSINELLO, P. Z. Influence of Storage on Darkening and Hardening of Slow- and Regular-Darkening Carioca Bean (Phaseolus vulgaris L.) Genotypes. Journal of Agricultural Studies, Las Vegas, v. 2, n. 2, p.87-104, 2014.

VINDIOLA, O. L.; SEIB, P. A.; HOSENEY, R. C. Accelerated development of the hard tocook state in beans. Cereal Foods World, Saint Paul, v. 31, n. 8, p.538-552, 1986. 